\title{
Matching ERS scatterometer based soil moisture patterns with simulations of a conceptual dual layer hydrologic model over Austria
}

\author{
J. Parajka ${ }^{1,3}$, V. Naeimi ${ }^{2}$, G. Blöschl ${ }^{1}$, and J. Komma ${ }^{1}$ \\ ${ }^{1}$ Institute for Hydraulic and Water Resources Engineering, Vienna University of Technology, Austria \\ ${ }^{2}$ Institute of Photogrammetry and Remote Sensing, Vienna University of Technology, Austria \\ ${ }^{3}$ Institute of Hydrology, Slovak Academy of Sciences, Bratislava, Slovakia
}

Received: 26 September 2008 - Published in Hydrol. Earth Syst. Sci. Discuss.: 24 November 2008

Revised: 30 January 2009 - Accepted: 3 February 2009 - Published: 23 February 2009

\begin{abstract}
This study compares ERS scatterometer top soil moisture observations with simulations of a dual layer conceptual hydrologic model. The comparison is performed for 148 Austrian catchments in the period 1991-2000. On average, about 5 to 7 scatterometer images per month with a mean spatial coverage of about $37 \%$ are available. The results indicate that the agreement between the two top soil moisture estimates changes with the season and the weight given to the scatterometer in hydrologic model calibration. The hydrologic model generally simulates larger top soil moisture values than are observed by the scatterometer. The differences tend to be smaller for lower altitudes and the winter season. The average correlation between the two estimates is more than 0.5 in the period from July to October, and about 0.2 in the winter months, depending on the period and calibration setting. Using both ERS scatterometer based soil moisture and runoff for model calibration provides more robust model parameters than using either of these two sources of information.
\end{abstract}

\section{Introduction}

Continuous progress in the remote sensing technology and advances in the retrieval and mapping concepts go in line with the efforts of testing their accuracy and applicability in different fields and disciplines. The recent advances in global soil moisture retrieval have received much attention in the hydrologic science, as the volume of water stored in the soils

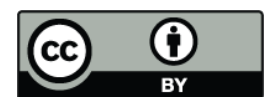

Correspondence to: J. Parajka (parajka@hydro.tuwien.ac.at) plays a critical role for many scientific and operational tasks. The knowledge of the actual soil moisture state is crucial information which helps hydrologists to predict the response of catchments to different precipitation forcing and indicates the vulnerability of regions to drought. Global coverage is appealing, however, due to its indirect way of retrieval and a coarse spatial resolution, the validation and comparison with other soil moisture estimates over different scales and regions is needed.

In the past, a few studies compared the global soil moisture estimates with field measurements. Soil moisture in-situ observations are fairly accurate but they are point measurements. It is in fact a challenging task to compare scatterometer soil moisture data, which represents large-scale variability, with field measurements since the scatterometer data is more sensitive to the atmospheric-forcing related component of soil moisture than the small-scale land surface related variability. Wagner et al. (1999) validated ERS scatterometer (SCAT) data with gravimetric soil moisture measurements in the $0-20 \mathrm{~cm}$ and $0-100 \mathrm{~cm}$ layers over 211 field sites in Ukraine in the period 1992-1996 and found mean correlations from 0.35 to 0.53 and from 0.33 to 0.49 in the $0-20 \mathrm{~cm}$ and $0-100 \mathrm{~cm}$ soil layers, respectively. In a more extensive comparison, Ceballos et al. (2005) validated scatterometer observations with field measurements from the REMEDHUS soil moisture station network (20 stations) in the central part of the Duero Basin located in West Spain. In this area they found mean square error between the scatterometer data and the average soil moisture in the $0-100 \mathrm{~cm}$ profile of $2.2 \mathrm{vol} \%$ and the coefficient of determination of 0.75 . Several similar experiments have shown beneficial information of SCAT soil moisture data in hydrological (Dirmeyer et al., 2004; Scipal et al., 2005; Parajka et al., 2005; Pellarin et al., 2006),

Published by Copernicus Publications on behalf of the European Geosciences Union. 
climate (Fontaine et al., 2006), meteorological (Zhao et al., 2006), and agro-meteorological (De Wit et al., 2007) studies.

One option for comparison and combination of satellite soil moisture estimates is their assimilation into hydrologic models. The rationale of combining hydrological models and satellite data is that even though both sources have clear limitations, are not defined in exactly the same way, and are associated with significant uncertainty it is their combination that should help reduce the uncertainty of the integrated estimates. The error structures of the two sources are likely different, so one would expect a combination of them to be less biased and exhibit less random error than any of them individually. The hypothesis of different error structures is plausible because of a number of reasons. Most importantly, the estimates come from completely different instruments, ground based instruments and spaceborne sensors, so one would also expect their errors to be different. Also, the models that estimate soil moisture in these two sources have different structures and they are calibrated in different ways.

Soil moisture assimilation has attracted a lot of attention in hydrology in the last decade (e.g., Hoeben and Troch, 2000; Houser et al., 2000; Walker et al., 2001; Francois et al., 2003; Parada and Liang, 2004 and 2008; Reichle and Koster, 2005; Crow et al. 2005). These studies have mostly focused on the assimilation of surface soil moisture data into land surface models. Some of these studies have been performed in a real time mode and have hence used a scheme for updating the state variables of the model. Houser et al. (2000) and Walker et al. (2001) assessed the relative merits of updating schemes including direct insertion, statistical corrections, Newtonian nudging, optimal interpolation, Kalman filtering and ensemble Kalman filtering. Pauwels et al. (2002) assimilated scatterometer soil moisture into a lumped hydrologic model and investigated the potential of improving runoff predictions. Another important application is the simulation mode where the soil moisture data are used in the calibration of hydrologic models together with other data sources. Such an application is presented, e.g., in Parajka et al. (2006), who compared root zone soil moisture estimates from the scatterometer data and a conceptual semi-distributed hydrologic model in Austria and examined the value of the scatterometer for improving hydrological simulations in both gauged and ungauged catchments. Their results showed that assimilation of the scatterometer data into the hydrologic model during the model calibration improved the agreement between the two soil moisture estimates without any significant decrease in runoff model efficiency. For the case of ungauged catchments, the scatterometer assimilation did not improve the runoff model simulations, but provided more consistent patterns of soil moisture estimates.

The main objective of this study is to compare the ERS scatterometer estimates with top soil moisture simulations of a dual-layer conceptual hydrologic model. The research focuses on the evaluation of the agreement between the simulated and observed top soil moisture in different seasons and elevation zones and on the assessment of the added value of scatterometer estimates in the multiple objective calibration of the hydrologic model for 148 catchments.

The paper goes beyond the existing studies in a number of ways. First, the most recent version of the scatterometer Global Soil Moisture product is used. The finer spatial resolution of the product shows the spatial variability of scatterometer top soil moisture in more detail. Second, the dual layer hydrologic model simulates directly the top soil moisture, while Parajka et al. (2006) compared root zone soil moisture. Third, the comparison of the soil moisture estimates is performed for different seasons and elevation zones, which allows to make inferences about the value of scatterometer data for hydrologic modeling.

The paper is organized as follows. The data section includes the description of the scatterometer, hydrologic and climatic datasets. The scatterometer subsection describes the retrieval algorithm and evaluates the spatial and temporal availability of the scatterometer observations over Austria. The method section presents the hydrologic model and its calibration and describes the criterions used for the comparison of the scatterometer and hydrologic model top soil moisture estimates. The results section examines the value of the scatterometer estimates in the hydrologic model calibration and compares the spatial and seasonal agreement between observed and simulated top soil moisture. Finally, the discussion and conclusion sections discuss the potential of the scatterometer observations in hydrological modeling and present some concluding remarks.

\section{Data}

The dataset used in this study includes a scatterometer top soil moisture estimates, climatic data used for driving a hydrologic model and runoff observations used for hydrologic model calibration and verification. The study region is Austria and the data are from the period 1991-2000.

\subsection{Scatterometer observations}

The scatterometer soil moisture dataset used in this study is the outcome of the latest reversion of the TU Wien soil moisture retrieval algorithm, WARP5 (Water Retrieval Package), which has been developed at the Institute of Photogrammetry and Remote Sensing at the Vienna University of Technology (TU Wien). In the TU Wien algorithm, which is basically a change detection method presented initially by Wagner et al. (1999), the long-term measurements of the scatterometer on board European Remote Sensing satellites (ERS-1 and ERS-2) are used to extract surface soil moisture dynamics. The new algorithm has been implemented in a discrete global grid with $12.5 \mathrm{~km}$ grid spacing and includes new features such as azimuthal anisotropy correction of the backscatter signal (Bartalis et al., 2006) and a soil moisture 
Table 1. Availability, mean spatial coverage and mean top soil moisture estimated from the scatterometer (ERS) images over Austria using different masking criteria. Masking criterion defines the cases when are the scatterometer pixel values taken into mean values estimation. The first and second values represent the mean top soil moisture (vol.\%) and mean spatial coverage (\%) over Austria, respectively. Period 1991-2000.

\begin{tabular}{lllllll}
\hline Month & $\begin{array}{l}\text { Availability } \\
\text { days] }\end{array}$ & Unmasked & $\begin{array}{l}\text { Air temperature } \\
>0^{\circ} \mathrm{C}\end{array}$ & $\begin{array}{l}\text { Air temperature } \\
>5^{\circ} \mathrm{C}\end{array}$ & $\begin{array}{l}\text { Snow depth } \\
<0.1 \mathrm{~cm}\end{array}$ & $\begin{array}{l}\text { Snow depth } \\
<2 \mathrm{~cm}\end{array}$ \\
\hline January & 81 & $42 / 42$ & $58 / 14$ & $67 / 2$ & $49 / 10$ & $48 / 10$ \\
February & 77 & $43 / 34$ & $48 / 20$ & $53 / 6$ & $51 / 10$ & $51 / 9$ \\
March & 82 & $48 / 41$ & $52 / 29$ & $56 / 13$ & $52 / 15$ & $52 / 14$ \\
April & 48 & $35 / 29$ & $35 / 26$ & $36 / 20$ & $36 / 20$ & $37 / 19$ \\
May & 75 & $41 / 38$ & $42 / 38$ & $42 / 35$ & $42 / 35$ & $42 / 35$ \\
June & 61 & $52 / 41$ & $52 / 41$ & $53 / 40$ & $52 / 41$ & $52 / 41$ \\
July & 57 & $58 / 35$ & $58 / 35$ & $59 / 34$ & $58 / 35$ & $58 / 35$ \\
August & 59 & $53 / 33$ & $53 / 33$ & $53 / 33$ & $53 / 33$ & $53 / 33$ \\
September & 71 & $52 / 36$ & $52 / 35$ & $53 / 34$ & $52 / 36$ & $52 / 35$ \\
October & 86 & $46 / 37$ & $47 / 35$ & $49 / 29$ & $67 / 34$ & $47 / 34$ \\
November & 83 & $54 / 37$ & $61 / 29$ & $64 / 13$ & $52 / 23$ & $50 / 23$ \\
December & 106 & $46 / 37$ & $62 / 15$ & $82 / 2$ & $5 / 11$ & $57 / 11$ \\
\hline
\end{tabular}

noise model (Naeimi et al., 2008a). Furthermore, the new algorithm utilizes the continuation of the soil moisture data retrieval from the Advanced Scatterometer (ASCAT), successor of the SCAT, on board the Meteorological Operational (METOP) satellite series, which will be operated until at least 2020. The new dataset has been made available on http://www.ipf.tuwien.ac.at/radar/.

Scatterometers onboard ERS satellites are active microwave instruments operating in C-band $(5.6 \mathrm{GHz})$ at $\mathrm{VV}$ polarization providing day and night time backscatter measurements unaffected by cloud cover. The three SCAT antennae illuminate radar beams looking at three different azimuthal angles $45^{\circ}, 90^{\circ}$, and $135^{\circ}$ with respect to the satellite's track and different incidence angles ranging from $18^{\circ}$ to $59^{\circ}$. Three concurrent backscatter measurements, so-called "triplets", are acquired at different viewing angles relating to $50 \mathrm{~km}$ cells that are oversampled to a $25 \mathrm{~km}$ orbit grid.

Low frequency microwaves $(1-10 \mathrm{GHz})$ are highly sensitive to the water content in the soil surface layer, although the surface roughness and vegetation also play an important role in backscattering from the surface. In the TU Wien algorithm, the multi-looking direction ability of scatterometer is used to describe the incidence angle behaviour of the backscatter signal as a seasonal function. The estimated incidence-angle dependency function is used for normalization of the backscatter signal to a unique reference incidence angle chosen as $40^{\circ}$ and also to eliminate vegetation contribution in. Eventually the normalized backscatter is scaled between the lowest and highest values ever measured within the long-term observations representing the driest and wettest conditions. In this way, corresponds to the relative soil moisture values at the topmost $2 \mathrm{~cm}$ of the soil and range between $0 \%$ and $100 \%$.

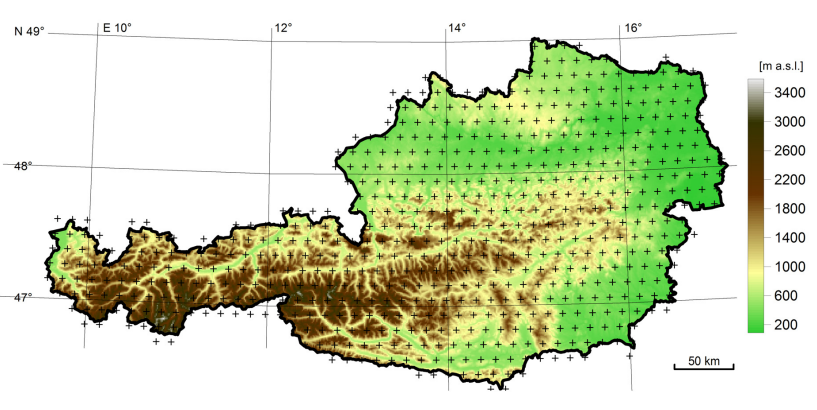

Fig. 1. Topography of Austria and location of grid centers of scatterometer top soil moisture estimates.

The location of the grid centers of the scatterometer data over Austria are presented in Fig. 1. In total, timeseries of top soil moisture are available at 621 grid cells. A typical example for 20 May 1996 is presented in Fig. 2 indicating that, often, top soil moisture is not available for the entire region. The ERS satellites carry an Instrument which combines the functions of a Synthetic Aperture Radar (SAR) and a Scatterometer, which are not operated simultaneously. The reduced temporal sampling is caused mainly by preferential switching to the SAR mode in this region. The mean spatial coverage ranges between $29.1 \%$ in April and $42.1 \%$ in January (Table 1). The mean top soil moisture estimated as the average of available scatterometer images varies from $35 \%$ in April to $58 \%$ in July and the availability in varies from 48 images in April to 106 images in December. However, the images in the winter months are often affected by snow and frozen ground, which affects the mapping accuracy of the retrieval algorithm. The estimation of soil moisture over snow covered or frozen ground is not possible, and thus 


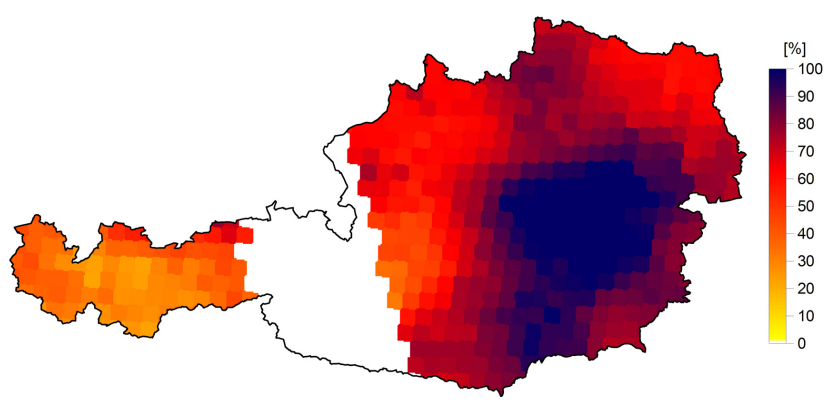

Fig. 2. Example of a scatterometer top soil moisture image, 20 May 1996.

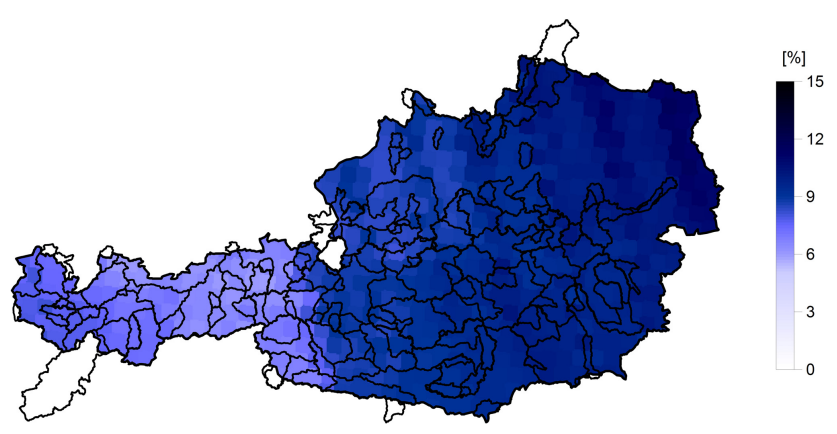

Fig. 3. Frequency of top soil moisture retrieval within the period 1 January 1991-31 December 2000.

these regions need to be masked. Table 1 shows the effects of different masking criteria on the change of the mean spatial coverage and the seasonal mean of top soil moisture images over Austria. The interpolated air temperature and snow depth maps (see the data section) were applied for detecting and masking scatterometer pixels which may be affected by snow or frozen ground. It is clear that the availability of scatterometer data decreases in winter. In January e.g., the mean spatial coverage drops from $42 \%$ (unmasked data) to $10 \%$ if snow depth data are used for masking and to $14 \%$ and $2.2 \%$ if the air temperature data are applied. The comparison of the change in top soil moisture mean over Austria indicates that the occurrence of snow over retrieved pixels decreases the top soil moisture. In January e.g., the mean top soil moisture increases from 42 vol.\% for unmasked data to 58 vol.\% for the positive air temperature data (Table 1).

The spatial variability in the frequency of top soil moisture retrieval in the period 1991-2000 is presented in Fig. 3. The spatial patterns indicate that in the eastern and central part of Austria, top soil moisture information is available on about $10-15 \%$ of the days, while in the Tirolian Alps, it is available on less than 5\% of the days of the period 1991-2000.

\subsection{Climatic and hydrologic data}

The soil moisture was analyzed in 148 gauged catchments. These catchments are in different physiographic and climatic zones and range in size from $25 \mathrm{~km}^{2}$ to $9770 \mathrm{~km}^{2}$ with a median of $369 \mathrm{~km}^{2}$. Daily runoff observations were available to calibrate and verify a hydrologic model. In preliminary analyses (e.g. Merz and Blöschl, 2004), the quality of the runoff data was checked and catchments that are subject to significant anthropogenic influences and/or where the water balance could not be closed were excluded from the data set. The inputs to the hydrologic modelling were prepared from daily measurements of precipitation at 1091 stations and air temperature at 240 climatic stations. For the identification of snow covered areas, the daily snow depth measurements observed at precipitation stations were applied. The precipitation and air temperature station data were spatially interpolated to regular $1 \times 1 \mathrm{~km}$ grid covering the entire Austria. External drift kriging was applied for the interpolation of precipitation and snow depth, and the least-squares trend prediction method was used for air temperatures interpolation (Pebesma, 2001). Potential evapotranspiration was subsequently estimated from air temperature grid maps and digital elevation model using a modified Blaney-Criddle method (Parajka et al., 2003; Mészároš and Miklánek, 2006). Next, time-series of input variables were extracted for different elevation zones in each selected catchment. For their determination ranges of $200 \mathrm{~m}$ were applied in each catchment, starting consistently from zero elevation ( $0 \mathrm{~m}$ a.s.1.). This enabled us to run independent simulations of water balance components (including soil moisture) in different elevation zones.

\section{Method}

\subsection{Hydrologic model}

Soil moisture state was simulated by a conceptual semidistributed hydrologic model that follows the structure of the HBV model. The model runs on a daily time step and consists of snow, soil moisture and flow routing routines. The soil moisture routine represents runoff generation and changes in the soil moisture state of the catchment. In contrast to a lumped representation of soil storage in the conventional HBV scheme, the model applied in this study uses a parsimonious dual layer soil representation developed at the TU Vienna (Komma et al., in preparation). The soil storage is represented by a thin skin soil layer at the surface sitting on the top of the main soil reservoir (Fig. 4). The skin soil layer represents a reservoir which is filled by rain and snow melt. If the capacity of the skin soil reservoir $L_{\text {skin }}$ is reached, the excess water $d Q_{\text {skin }}$ is divided into two components. The fraction $d Q$ becomes runoff. The fraction $d S_{s}$ increases the main soil moisture $S_{s}$. The soil moisture of the skin soil reservoir is reduced by a fraction of the actual evaporation $A E T_{\text {skin }}=(1-\varphi) \times A E T$, where $A E T$ is the actual evaporation and the parameter $\phi$ subdivides $A E T$ into evaporation from the main $A E T_{\text {main }}$ and the skin soil layer $A E T_{\text {skin. The }}$ skin soil reservoir and the main soil reservoir are connected 


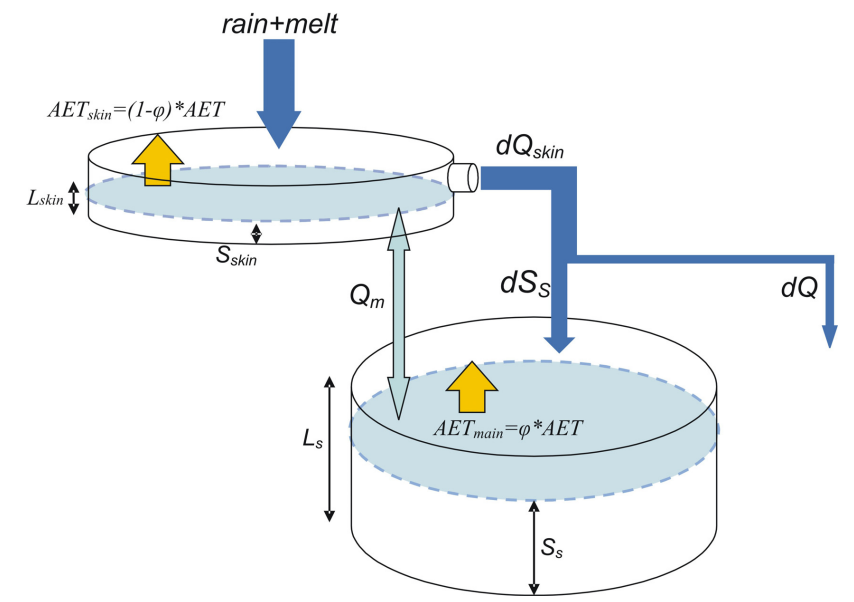

Fig. 4. General schematic of the Dual Layer soil moisture accounting scheme introduced in the HBV model concept.

by a bidirectional moisture flux $Q_{m}$ which is assumed to be a linear function of the vertical soil moisture gradient $\Delta_{m}$ :

$Q_{m}=\Delta_{m} \times \alpha_{m}$,

where $\alpha_{m}$ is a transfer parameter. If the skin soil moisture is greater than the soil moisture of the main layer, percolation from the skin to the main soil layer occurs $\left(Q_{m}>0\right)$. If the skin soil moisture is less than soil moisture of the main layer, capillary raise from the main to the skin soil layer occurs $\left(Q_{m}<0\right)$. The vertical soil moisture gradient is defined as the difference between the relative soil moisture in the skin soil reservoir and that in the main soil reservoir, i.e.:

$\Delta_{m}=\frac{S_{\text {skin }}}{L_{\text {skin }}}-\frac{S_{s}}{L_{s}}$,

where $S_{\text {skin }}$ stands for the skin soil moisture, $L_{\text {skin }}$ defines the capacity of the skin soil reservoir, and $S_{S}$ and $L_{S}$ are the moisture state and the capacity of the main soil reservoir.

The dual layer soil moisture accounting scheme uses three parameters. These are the capacity of the skin soil reservoir $L_{\text {skin }}$, the transfer parameter $\alpha_{m}$ and the AET subdivision parameter $\phi$.

A detailed information about the remaining part of the hydrological model is given in appendix of Parajka et al. (2007). The hydrologic model with the dual layer extension has 18 parameters. In this study four parameters were fixed $\left(T_{R}=2^{\circ} \mathrm{C}, T_{S}=-2^{\circ} \mathrm{C}, C_{R}=26.5\right.$ day $^{2} . \mathrm{m}^{-1}, B_{\mathrm{MAX}}=10$ days; for details see Parajka et al. 2007) and 14 parameters (Table 2) were estimated by automatic model calibration.

3.2 Model efficiency to observed runoff and top soil moisture

Calibration and validation of the hydrologic model is based on a number of efficiency measures and error measures that
Table 2. Hydrologic model parameters and lower $\left(p_{l}\right)$ and upper $\left(p_{u}\right)$ bounds used in model calibration. A more detailed description of the model parameters and the model structure is given in the appendix of Parajka et al. (2007).

\begin{tabular}{lcrr}
\hline Model parameter $j$ & Model component & $p_{l}$ & $p_{u}$ \\
\hline$S C F[-]$ & Snow & 0.9 & 1.5 \\
$D D F\left[\mathrm{~mm} /{ }^{\circ} \mathrm{C}\right.$ day $]$ & Snow & 0.0 & 5.0 \\
$T_{M}\left[{ }^{\circ} \mathrm{C}\right]$ & Snow & -2.0 & 3.0 \\
$L_{\text {skin }}[\mathrm{mm}]$ & Top soil & 1.0 & 10.0 \\
$\alpha_{m}[\mathrm{~mm} /$ day $]$ & Top soil & 5.0 & 15.0 \\
$\phi[-]$ & Top soil & 0.8 & 0.95 \\
$L P / F C[-]$ & Main soil & 0.0 & 1.0 \\
$F C[\mathrm{~mm}]$ & Main soil & 0.0 & 600 \\
$\beta[-]$ & Main soil & 0.0 & 20 \\
$K_{0}[$ days $]$ & Runoff & 1.0 & 2.0 \\
$K_{1}[$ days $]$ & Runoff & 2.0 & 30 \\
$K_{2}[$ days $]$ & Runoff & 30 & 250 \\
$C_{P}[\mathrm{~mm} /$ day $]$ & Runoff & 0.0 & 8.0 \\
$L S_{U Z}[\mathrm{~mm}]$ & Runoff & 1.0 & 100 \\
\hline
\end{tabular}

represent the match (or mismatch) of the simulation and the observed data. For runoff, the Nash-Sutcliffe Model efficiency $\left(M_{E}\right)$ has been used in two variants, $M_{E}$ and $M_{E}^{\log }$, that emphasize high and low flows, respectively:

$M_{E}=1-\frac{\sum_{i=1}^{n}\left(Q_{\mathrm{obs}, i}-Q_{\mathrm{sim}, i}\right)^{2}}{\sum_{i=1}^{n}\left(Q_{\mathrm{obs}, i}-\overline{Q_{\mathrm{obs}}}\right)^{2}}$

and

$M_{E}^{\log }=1-\frac{\sum_{i=1}^{n}\left(\log \left(Q_{\mathrm{obs}, i}\right)-\log \left(Q_{\mathrm{sim}, i}\right)\right)^{2}}{\sum_{i=1}^{n}\left(\log \left(Q_{\mathrm{obs}, i}\right)-\log \left(\overline{Q_{\mathrm{obs}}}\right)\right)^{2}}$

where $Q_{\text {sim }, i}$ is the simulated runoff on day $i, Q_{\mathrm{obs}, i}$ is the observed runoff, $\overline{Q_{\text {obs }}}$ is the average of the observed runoff over the calibration (or verification) period of $n$ days.

The agreement between observed (scatterometer) and simulated (hydrologic model) top soil moisture has been described by the correlation coefficient $r$ and the mean difference measure $S_{B}$. In order to reduce the effects of snow cover on the accuracy of scatterometer soil moisture, these agreement measures were calculated only for days without snow cover. The correlation coefficient is estimated according following relation:

$$
r=\frac{\sum_{j=1}^{m}\left(S_{\mathrm{obs}, j}-\bar{S}_{\mathrm{obs}}\right) \times\left(S_{\mathrm{sim}, j}-\bar{S}_{\mathrm{sim}}\right)}{\sqrt{\sum_{j=1}^{m}\left(S_{\mathrm{obs}, j}-\bar{S}_{\mathrm{obs}}\right)^{2} \times \sum_{j=1}^{m}\left(S_{\mathrm{sim}, j}-\bar{S}_{\mathrm{sim}}\right)^{2}}}
$$


where $S_{\mathrm{sim}, j}$ is the top soil moisture simulated by the hydrologic model on day $j, S_{\mathrm{obs}, j}$ is the scatterometer top soil moisture on day, $j$ and $\bar{S}_{\text {obs }}$ and $\bar{S}_{\text {sim }}$ are the averages of the observed and simulated top soil moisture over the period of scatterometer observations without snow of $m$ days. The scatterometer $S_{\mathrm{obs}, j}$ and simulated top soil moisture $S_{\mathrm{sim}, j}$ are defined in relative units [\%], where $S_{\mathrm{sim}, j}$ is defined as the skin soil moisture to capacity of skin reservoir ratio:

$S_{\text {sim }, j}=\frac{S_{\text {skin }}}{L_{\text {skin }}}$

and they represent the averages over particular elevation zone of a catchment. The zonal scatterometer estimates are averaged from $12.5 \mathrm{~km}$ grids (the grid resolution is presented in Fig. 1), the simulation by the hydrologic model are independently performed for each elevation zone.

The $S_{B}$ measure represents the difference between the scatterometer $S_{\text {obs }}$ and hydrologic model $S_{\text {sim }}$ top soil moisture and is defined as:

$S_{B}=\frac{\sum_{j=1}^{m}\left(S_{\mathrm{sim}, j}-S_{\mathrm{obs}, j}\right)}{m}$

i.e., for a positive $S_{B}$ value the hydrologic model overestimates the scatterometer data.

\subsection{Hydrologic model calibration}

Simulation of soil moisture by the hydrologic model requires the estimation of model parameters. In this regional study we applied an automatic calibration approach, which is based on the SCE-UA global optimization algorithm (Duan et al., 1992). The calibration is based on minimizing a compound objective function $Z_{M}$ :

$Z_{M}=\left(1-w_{r}\right) \times Z_{S}+w_{r} \times Z_{Q}$

where $Z_{Q}$ and $Z_{S}$ relate to the observed runoff and the top soil moisture data and $w_{r}$ weights these two different objectives. Equation(7) was applied to test three different calibration variants. In a first variant, termed runoff only calibration, we emulate the usual model calibration and estimate the parameters of the hydrologic model by minimising the differences between observed and simulated runoff alone. In this case, the weight $w_{r}$ is set to unity ( $w_{r}=1.0$, Eq. 7) and the runoff objective function is defined as:

$Z_{Q}=w_{Q} \times\left(1-M_{E}\right)+\left(1-w_{Q}\right) \times\left(1-M_{E}^{\log }\right)$

where the weight $w_{Q}$ is set to 0.5 . The idea of Eq. (8) is to combine two agreement measures $M_{E}$ and $M_{E}^{\log }$, that equally emphasize high and low flows.

In a second variant, termed soil moisture only calibration, we emulate the case, where only observed scatterometer data are used for constraining the hydrologic model parameters.

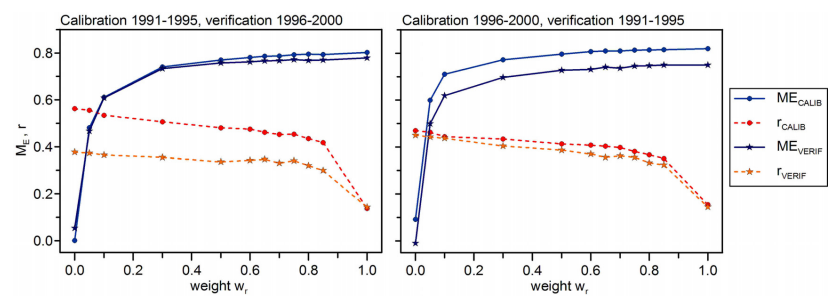

Fig. 5. Sensitivity of the runoff model efficiency $M_{E}$ (solid lines) and top soil moisture correlation $r$ (dashed lines) to the weight $w_{r}$ (Eq. 7). Median over 148 catchments.

In this situation, the weight $w_{r}$ (Eq. 7) is set to zero $\left(w_{r}=0.0\right.$, Eq. 7) and the soil moisture objective function is defined as:

$Z_{S}=1-r$

where $r$ is the correlation coefficient (Eq. 5) between observed and simulated top soil moisture. The correlation was estimated using the top soil moisture observations and the corresponding simulations in different elevation zones of a particular catchment.

In a third variant, termed multiple-objective calibration, we use both runoff and scatterometer top soil moisture data to calibrate the model by minimizing the compound objective function $Z_{M}$ (Eq. 7). In this study the weight $w_{r}$ is chosen on the basis of sensitivity analyses (see Results section). The sensitivity analyses investigate the change of runoff and top soil moisture model efficiencies with respect to the selection of the weight $w_{r}$.

\section{Results}

The variation of runoff and top soil moisture model efficiencies with respect to change of the weight $w_{r}$ is presented in Fig. 5. Figure 5 shows the median of runoff and top soil moisture efficiencies estimated over 148 catchments in two calibration and verification periods. Such an evaluation follows the split-sample test of Klemeš (1986), where two five-year periods are used in turn for calibration and validation. The left panel shows the model performance in the calibration period 1991-1995 and the verification period 1996-2000; the right panel shows the model performance in the calibration period 1996-2000 and the verification period 1991-1995. The sensitivity analysis indicates that the runoff model efficiency ( $M_{E}$, solid lines) changes only little for $w_{r}$ between 0.3 and 1.0. Only as $w_{r}$ decreases below $0.10, M_{E}$ begins to drop as very little importance is given to the runoff data in the calibration. The patterns of top soil moisture correlation $(r$, dashed lines) show a slow decrease for $w_{r}$ between 0.0 and 0.80 . When the weight $w_{r}$ exceeds $0.85, r$ begins to drop as very little importance is given to the scatterometer data in the calibration. There is a quite large range of $w_{r}$ (between 0.3 and 0.8 ) where both 
Table 3. Runoff model efficiency $M_{E}$ (Eq. 3) evaluated for three calibration variants: (1) runoff only calibration $\left(w_{r}=1.0\right)$, (2) soil moisture only calibration $\left(w_{r}=0.0\right)$ and (3) multiple objective calibration $\left(w_{r}=0.65\right)$. The first and second values represent the median and percentile difference (p75\%-p25\%) over 148 catchments, respectively.

\begin{tabular}{lllll}
\hline Calibration variant & Calibration 1991-1995 & Verification 1996-2000 & Calibration 1996-2000 & Verification 1991-1995 \\
\hline$w_{r}=1.0$ & $0.80 / 0.13$ & $0.78 / 0.17$ & $0.82 / 0.13$ & $0.75 / 0.20$ \\
$w_{r}=0.65$ & $0.79 / 0.12$ & $0.77 / 0.16$ & $0.81 / 0.13$ & $0.74 / 0.19$ \\
$w_{r}=0.0$ & $0.00 / 0.80$ & $0.05 / 0.65$ & $0.09 / 0.57$ & $-0.01 / 0.77$ \\
\hline
\end{tabular}

the runoff efficiency is large and the soil moisture correlation is practically constant. However, the limiting cases, where only the runoff component $\left(w_{r}=1\right)$ or only the soil moisture component $\left(w_{r}=0\right)$ is used in model calibration show significant differences in runoff and top soil moisture efficiencies. This indicates that if only runoff is used in the calibration the agreement between top soil moisture observations and simulations is poor and vice versa. Based on these sensitivity tests, a weight of $w_{r}=0.65$ was selected as a representative trade-off between the runoff and top soil moisture objectives and was applied in the remainder of this paper for the simulation of top soil moisture and runoff in the multiple objective calibration variant.

The efficiency of the hydrologic model to simulate runoff is presented in Table 3. The assessment of the runoff only variant $\left(w_{r}=1.0, \mathrm{Eq} .7\right)$ shows that the medians of the runoff model efficiencies over 148 catchments are 0.80 and 0.82 in the calibration and 0.78 and 0.75 in the verification periods. These simulations represent a typical setup in rainfall-runoff modeling. A similar runoff model performance is obtained by the multiple objective calibration variant $\left(w_{r}=0.65\right)$. The medians of runoff $M_{E}$ are only somewhat smaller, 0.79 and 0.81 in the calibration and 0.77 and 0.74 in the verification periods. The efficiency of both calibration variants indicates a good overall agreement between observed and simulated runoff. Significantly poorer runoff model performance is obtained by the calibration variant that uses only the top soil moisture $\left(w_{r}=0.0\right)$ in hydrologic model calibration. The medians of runoff $M_{E}$ in the calibration and verification periods are around zero, which indicates that constraining the hydrologic model only by the scatterometer soil moisture is not sufficient for reliable runoff simulations. The scatter or percentile difference indicates a large variability of runoff model performance between the 148 catchments; however for the majority of the catchments the runoff model performance is very poor.

Table 4 gives the median and percentile difference of the correlation coefficient $r$ estimated between observed (scatterometer) and simulated (hydrologic model) top soil moisture. The simulations based on the model parameters constrained by observed runoff only $\left(w_{r}=1.0\right)$ do not match well with the scatterometer estimates. The correlation coefficient does not differ between the calibration and verification pe- riods, but the median over 148 catchments is small, ranging from 0.14 to 0.16 . This indicates only a poor relationship between the two top soil moisture estimates. A better agreement is obtained by the simulations that use both runoff and top soil moisture in the model parameter optimization $\left(w_{r}=0.65\right)$. The medians of $r$ are 0.40 and 0.46 in the calibration periods and slightly drop to 0.33 and 0.36 in the verification periods. As one would expect, the best agreement between the top soil moisture estimates are obtained by the simulations based on the soil moisture data calibration $\left(w_{r}=0.0\right)$. The median is 0.56 and 0.47 in the calibration periods and 0.38 and 0.45 in the verification periods. For this case, the scatter of the correlation efficiencies over the 148 catchments is the smallest, 0.14 and 0.11 in the calibration periods and 0.14 and 0.21 in the verification periods.

Table 5 summarizes the difference $S_{B}$ between model simulations and scatterometer estimates of the top soil moisture. In contrast to the correlation coefficient, the $S_{B}$ difference is not directly included in the model parameter calibration and thus is an independent efficiency measure. Table 5 indicates that the hydrologic model simulations generally overestimate the scatterometer observations (case where $S_{B}>0$ ). The largest overestimation is observed for the calibration variant which uses only measured runoff in parameter calibration $\left(w_{r}=1.0\right)$. In this case, the median of $S_{B}$ ranges from $21.2 \%$ to $23.3 \%$ in the calibration periods and from $20.3 \%$ to $23.8 \%$ in the verification periods. Only slightly lower values of $S_{B}$ are obtained by the multiple objective calibration $\left(w_{r}=0.65\right)$; the medians range from $14.7 \%$ to $23.8 \%$ and from $19.9 \%$ to $23.4 \%$ in the calibration and verification periods, respectively. Calibration against the measured top soil moisture alone resulted in smaller difference. The median of $S_{B}$ is $3.0 \%$ and $13.7 \%$ in the calibration periods, and increases to $18.6 \%$ and $13.8 \%$ in the verification periods.

A typical simulation of the dual layer hydrologic model for the Furtmühle catchment $\left(256.4 \mathrm{~km}^{2}\right.$, gauge elevation $504 \mathrm{~m}$ a.s.1.) is presented in Fig. 6. The top part (Figure 6, A) shows the simulations for a runoff only case (wr=1.0); the bottom part (Fig. 6b) shows a multiple objective case (wr $=0.65$ ). Both cases illustrate a representative runoff model performance, which is very close to the median over the 148 catchments $\left(M_{E}=0.80\right)$. Noticeable differences are observed for the top soil moisture agreement. The runoff only and 
Table 4. Correlation $r$ (Eq. 5) between scatterometer and hydrologic model top soil moisture estimates evaluated for three calibration variants: (1) runoff only calibration $\left(w_{r}=1.0\right)$, (2) soil moisture only calibration $\left(w_{r}=0.0\right)$ and (3) multiple objective calibration $\left(w_{r}=0.65\right)$. The first and second values represent the median and percentile difference (p75\%-p25\%) over 148 catchments, respectively.

\begin{tabular}{lllll}
\hline Calibration variant & Calibration 1991-1995 & Verification 1996-2000 & Calibration 1996-2000 & Verification 1991-1995 \\
\hline$w_{r}=1.0$ & $0.14 / 0.23$ & $0.14 / 0.16$ & $0.16 / 0.20$ & $0.15 / 0.27$ \\
$w_{r}=0.65$ & $0.46 / 0.17$ & $0.33 / 0.18$ & $0.40 / 0.15$ & $0.36 / 0.24$ \\
$w_{r}=0.0$ & $0.56 / 0.14$ & $0.38 / 0.14$ & $0.47 / 0.11$ & $0.45 / 0.21$ \\
\hline
\end{tabular}

Table 5. Soil moisture difference $S_{B}$ (Eq. 6) between hydrologic model and scatterometer top soil moisture estimates evaluated for three calibration variants: (1) runoff only calibration $\left(w_{r}=1.0\right),(2)$ soil moisture only calibration $\left(w_{r}=0.0\right)$ and (3) multiple objective calibration $\left(w_{r}=0.65\right)$. The first and second values represent the median and percentile difference ( $\left.\mathrm{p} 75 \%-\mathrm{p} 25 \%\right)$ over 148 catchments, respectively.

\begin{tabular}{lllll}
\hline Calibration variant & Calibration 1991-1995 & Verification $1996-2000$ & Calibration 1996-2000 & Verification 1991-1995 \\
\hline$w_{r}=1.0$ & $21.2 / 18.2$ & $23.8 / 14.9$ & $23.3 / 16.6$ & $20.3 / 14.4$ \\
$w_{r}=0.65$ & $14.7 / 18.8$ & $23.4 / 16.1$ & $23.8 / 16.7$ & $19.9 / 14.5$ \\
$w_{r}=0.0$ & $3.0 / 17.8$ & $18.6 / 20.3$ & $13.7 / 21.8$ & $13.8 / 16.3$ \\
\hline
\end{tabular}

multiple objective cases show a very poor $(\mathrm{r}=0.04)$ and very good $(r=0.69)$ agreement between the top soil moisture estimates in the calibration period, respectively. The top panel of both parts compares the soil moisture simulations and scatterometer observations (points) in one elevation zone and displays the observed snow depth data in October, November and April. The soil moisture simulation dynamics is plotted separately for the top soil layer (light brown line) and the main soil layer (black line). The results show that the calibration of the model against runoff only does not enable a coherent simulation of the top soil layer with the scatterometer estimates. On the other hand, the simulations obtained by the multiple objective case match very well with the scatterometer, except in winter and spring, when snow occurs. As is documented in Table 1, the snow cover affects the scatterometer top soil moisture retrieval and often leads to the underestimation of moisture available in the skin soil layer. The comparison of the bottom soil layer dynamics indicates that for this particular example, the model calibrated to runoff only simulates higher relative soil moisture contents in the spring months, while the differences to the multiple objective case in summer are not significant. The bottom panel of each part shows observed precipitation and compares the runoff observations with the model simulations. Interestingly, the plot demonstrates the influence of the soil storage state on the runoff response of the catchment to precipitation forcing, as the dry catchment conditions at the beginning of June reduce the runoff response for both cases remarkably. On the other hand, in October, similar precipitation events caused a significantly larger runoff response.

Hydrol. Earth Syst. Sci., 13, 259-271, 2009
The spatial patterns of the runoff efficiencies $\left(M_{E}\right)$, soil moisture correlations $(r)$ and differences $\left(S_{B}\right)$ efficiencies in the calibration (1991-1995) period are presented in Fig. 7. Top, centre and bottom panels of Figure 8 show the corresponding evaluations in the verification period 1996-2000. The spatial patterns of $M_{E}$ are very similar for both calibration variants and simulation periods. The hydrologic model simulates the runoff in the wet alpine regions in the West and Central Austria very well. The simulations are poorer in the dry flatland regions situated mainly in the eastern part of Austria. Obviously, a slight decrease in the runoff model performance is observed between the calibration and verification periods.

The main differences between the calibration variants are the spatial patterns of the top soil moisture correlation. The top soil moisture simulation based on parameters optimized against runoff only does not match well with the scatterometer estimates. The correlations are especially poor in the alpine region in the West and in some catchments these are even negative. An exception is found in the northern prealpine and northern/eastern lowland areas, where the relationship between the two soil moisture estimates seems to be more significant. Much better agreement is simulated by the model parameters optimized to both runoff and top soil moisture (maps on the right). The correlations are remarkably higher in the alpine regions in the western and central parts of Austria. Interestingly, also for the multiple objective calibration variant a distinct boundary in the degree of correlation exists between the central and southern parts of the Austria. In the southern part the correlation is clearly weaker. This may be related to the less persistent weather patterns south of the main ridge of the Alps. South of the 

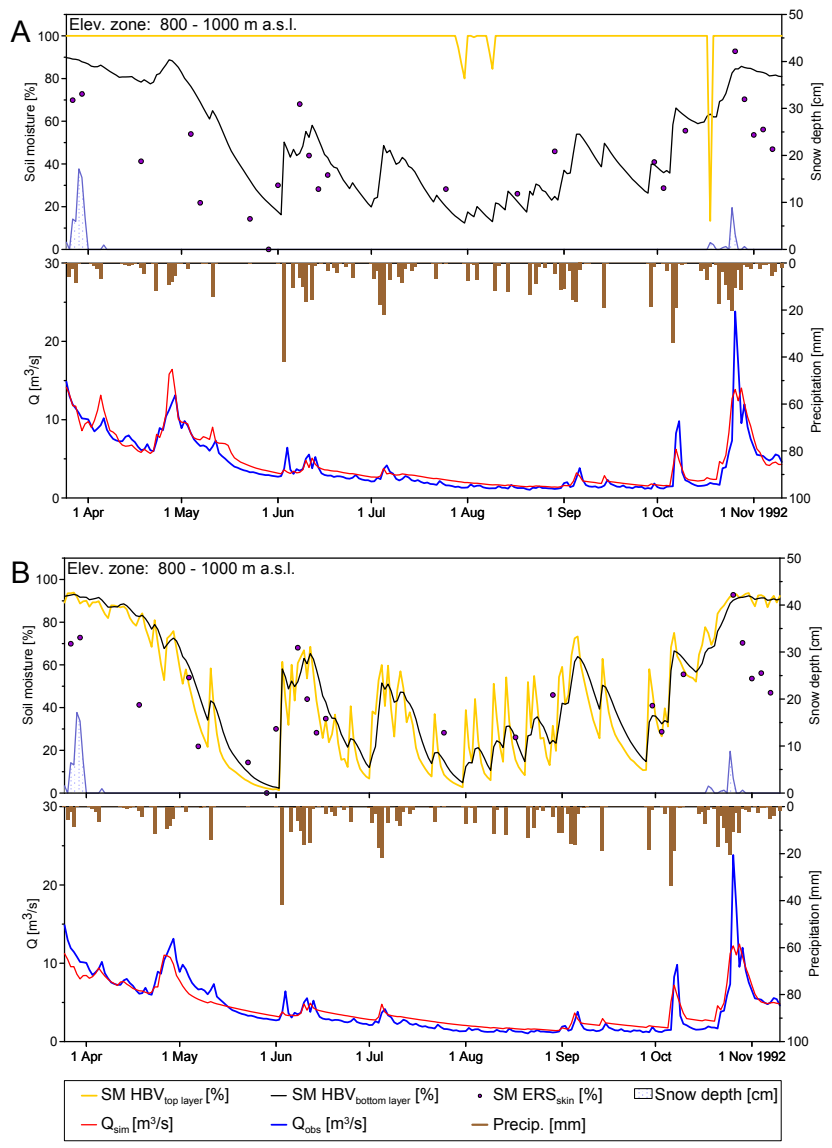

Fig. 6. Comparison of scatterometer (ERS) and hydrologic model (HBV) top soil moisture estimates (top panel) and runoff observation and model simulation (bottom panel). The example shows: (A) a runoff only case (weight $w_{r}=1.0$ ) and (B) multiple objective case (weight $w_{r}=0.65$ ) for part of the calibration period in the Furtmühle catchment $\left(256 \mathrm{~km}^{2}\right)$.

Alps both precipitation and snow cover are more variable in time than it is in the northern part of the Alps.

The maps at the bottom of Figs. 7 and 8 exhibit the spatial variation in the soil moisture difference. In the western alpine part of Austria, the top soil moisture simulations are very similar with respect to the scatterometer data. In contrast, the hydrologic model significantly overestimates top soil moisture in catchments located in the southern and south-eastern part of Austria. However, this may be also interpreted as the underestimation of soil moisture by scatterometer retrieval in these regions. In the verification period (Fig. 8), only a few catchments in the western and central part of Austria have similar top soil moisture estimates, in most of the catchments the hydrologic model tends to overestimate the scatterometer observations. The spatial patterns of the $S_{B}$ difference are relatively similar for both calibration variants in the calibration period, but in the verification period distinct differences are observed. There is small difference in the south-eastern

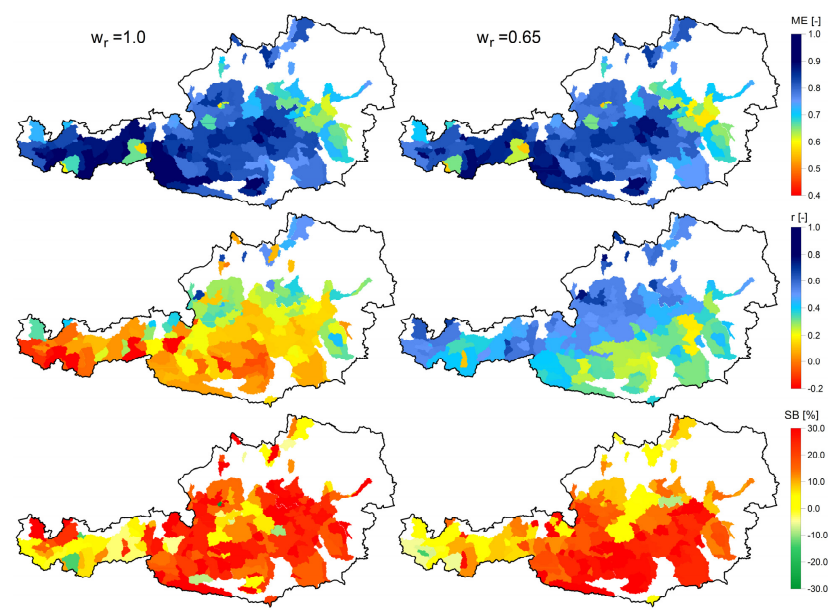

Fig. 7. Spatial patterns of the runoff model efficiency $M_{E}$ (top panel), top soil moisture correlation $r$ (middle panel) and the difference between the hydrologic model and the scatterometer top soil moisture $S_{B}$ (bottom panel) in the calibration period 1991-1995. The left panels show single objective ( $w_{r}=1.0$, to runoff only) efficiencies, the right panels show multiple objective $\left(w_{r}=0.65\right)$ efficiencies.

catchments and the catchments located in central and Western Austria. Interestingly, in some catchments, where the correlation between the top soil moisture estimates are high (e.g. in central Austria), the mean $S_{B}$ difference is larger than $20 \%$. This indicates that, even if the scatterometer estimates are in good agreement with the hydrologic model simulations, the model may overestimate the scatterometer top soil moisture substantially.

A more detailed analysis of the temporal and altitudinal variability of the agreement of the two top soil moisture estimates is presented in Figs. 9 and 10. Figure 9 shows the seasonal variability of the correlation coefficients (top panel) and the $S_{B}$ difference (bottom panel) in the calibration (1991-1995) and verification (1996-2000) periods. The largest medians of the correlation coefficient occur between July and October, and between April and October for the multiple objective calibration $\left(w_{r}=0.65\right)$ and the soil moisture only calibration $\left(w_{r}=0.0\right)$, respectively. The largest median in the verification period is observed in August for all three calibration variants. The seasonal variability of the top soil moisture difference indicates that the two calibration variants that use runoff data $\left(w_{r}=1.0\right.$ and $\left.w_{r}=0.65\right)$ overestimate the scatterometer top soil moisture in every season. Interestingly the overestimation is larger in the summer than in the winter. The difference is much smaller for the variant that uses only soil moisture $\left(w_{r}=0.0\right)$ in the calibration period. However, in the verification period the difference increases.

The variation of the top soil moisture correlation and difference in different elevation zones is analyzed in Fig. 10. There does not appear to exist a consistent relationship 


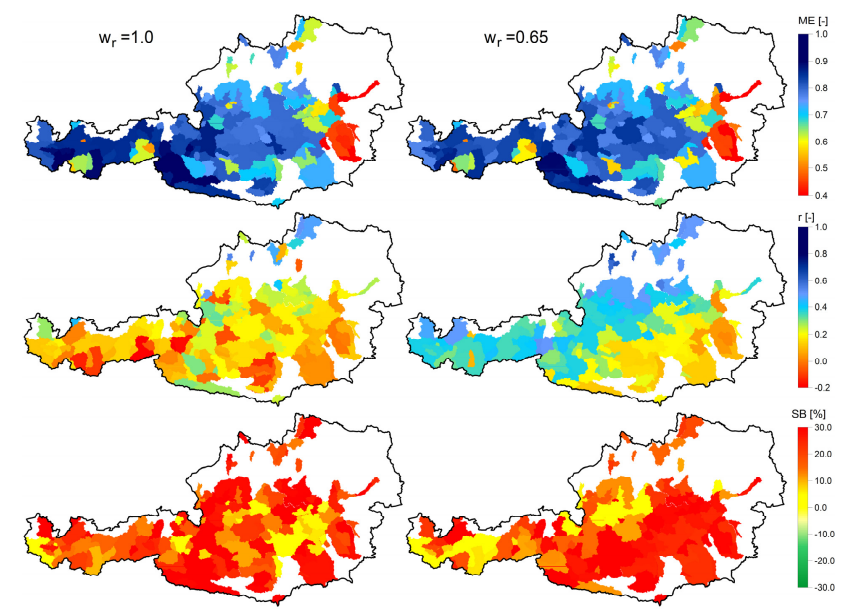

Fig. 8. Spatial patterns of the runoff model efficiency $M_{E}$ (top panel), top soil moisture correlation $r$ (middle panel) and the difference between the hydrologic model and the scatterometer top soil moisture $S_{B}$ (bottom panel) in the verification period 1996-2000. The left panels show single objective ( $w_{r}=1.0$, to runoff only) efficiencies, the right panels show multiple objective $\left(w_{r}=0.65\right)$ efficiencies.

between correlation and altitude (middle panels). In the calibration period (left panels), there is observed a weak tendency of decreasing correlation with elevation The evaluation of the soil moisture difference (bottom panels) shows a general increase with elevation for both the calibration and verification periods. Exceptions are the highest elevation zones, where smaller differences are observed. However, these elevation zones are represented only by few catchments and thus may be not considered as a representative dataset.

Together with the evaluation of hydrologic model performance, it is also interesting to assess the effects of different calibration settings on the uncertainty of hydrologic model parameters. The uncertainty is defined by the correlation coefficient estimated between model parameters from two different calibration periods (1991-1995 and 1996-2000). The comparison of the correlations (Table 6) indicates that the use of additional top soil moisture data in model calibration reduced the uncertainty for the parameters representing the top soil moisture and, interestingly, snow cover dynamics. The largest correlation is obtained for the snow correction factor $S C F(0.83)$ and the maximum capacity of the top soil reservoir $L_{\text {skin }}(0.70)$. The most uncertain parameters are the transfer scaling factor $\alpha_{m}$ in the runoff only variant $\left(w_{r}=1.0\right)$, the limit for potential evaporation ratio $L P / F C$ in the multiple calibration $\left(w_{r}=0.65\right.$ variant $)$ and the runoff storage coefficient $K_{0}$ in the soil moisture only variant $\left(w_{r}=0.0\right)$. An example of the variability of the model parameters that represent the top soil layer of the hydrologic model is presented in Fig. 11. Figure 11 shows the cumulative distribution functions of the $L_{\text {skin }}, \phi$ and $\alpha_{m}$ model parameters obtained by different calibration variants $\left(w_{r}=1.0, w_{r}=0.65\right.$ and

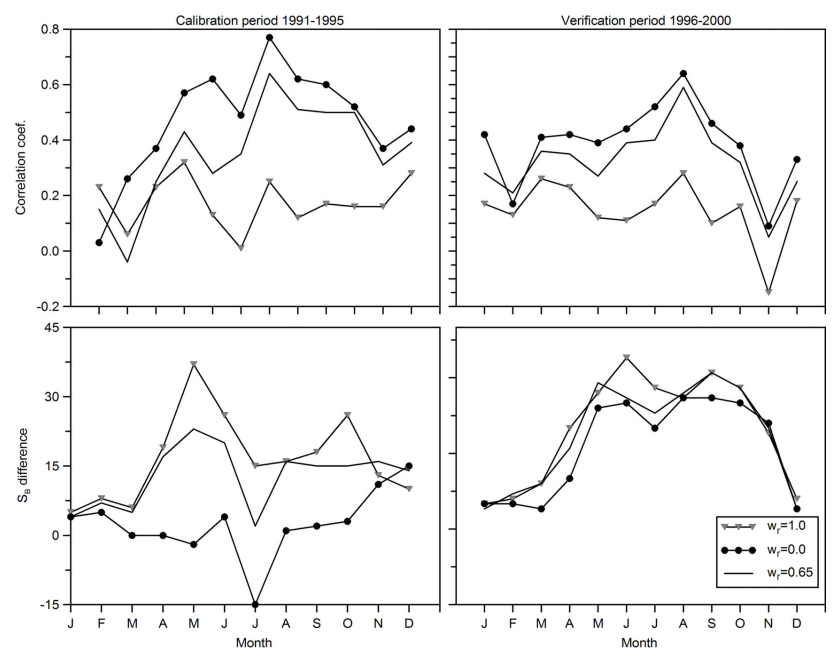

Fig. 9. Correlation coefficient $r$ and the $S_{B}$ difference between scatterometer and hydrologic model top soil moisture simulations in the calibration (left) and verification (right) periods analysed by season. The simulation represents three calibration variants: (1) runoff only calibration $\left(w_{r} 1.0\right),(2)$ soil moisture only calibration $\left(w_{r}=0.0\right)$ and (3) the multiple objective calibration $\left(w_{r}=0.65\right)$. The correlation $r$ and $S_{B}$ difference represent the median over 148 catchments.

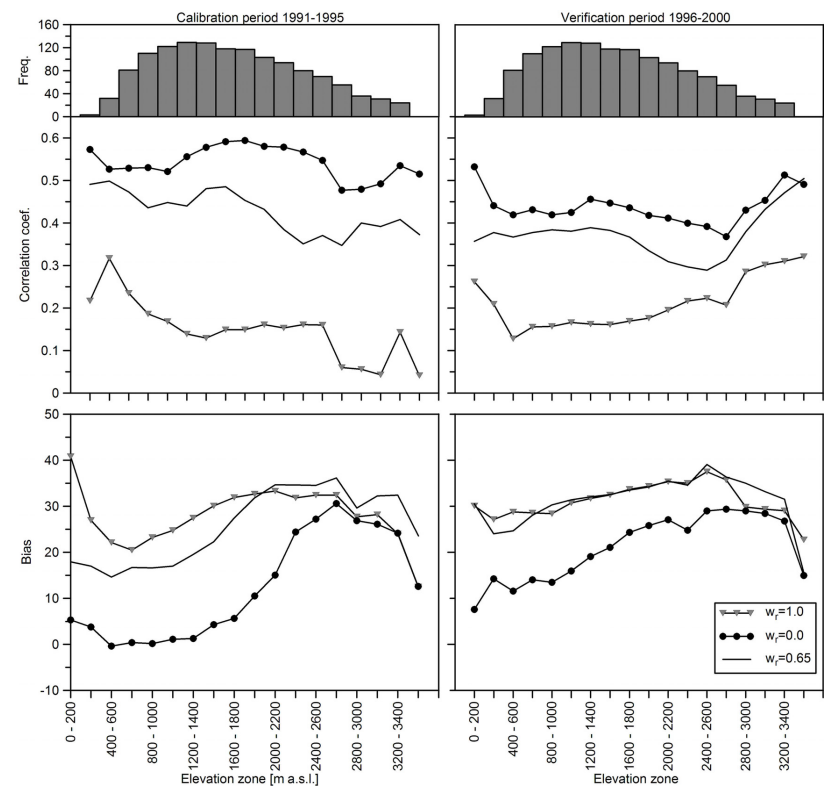

Fig. 10. Correlation coefficient $r$ and the $S_{B}$ difference between scatterometer and hydrologic model top soil moisture simulations in the calibration (left) and verification (right) periods analysed by altitude. The simulation represents three calibration variants: (1) runoff only calibration $\left(w_{r}=1.0\right)$, (2) soil moisture only calibration $\left(w_{r}=0.0\right)$ and (3) the multiple objective calibration $\left(w_{r}=0.65\right)$. The correlation $r$ and $S_{B}$ difference represent the median over 148 catchments. 
Table 6. Parameter uncertainty evaluated for three calibration variants: (1) runoff only calibration $\left(w_{r}=1.0\right)$, (2) soil moisture only calibration $\left(w_{r}=0.0\right)$ and (3) multiple objective calibration $\left(w_{r}=0.65\right)$. The uncertainty is defined by the correlation coefficient between the model parameters calibrated for two independent periods (1991-1995 and 1996-2000).

\begin{tabular}{lllr}
\hline \multirow{2}{*}{ Model parameter } & \multicolumn{3}{c}{ Calibration variant } \\
\cline { 2 - 4 } & $w_{r}=1.0$ & $w_{r}=0.65$ & $w_{r}=0.0$ \\
\hline$S C F[-]$ & 0.72 & 0.83 & 0.23 \\
$D D F\left[\mathrm{~mm} /{ }^{\circ} \mathrm{C}\right.$ day $]$ & 0.55 & 0.64 & 0.31 \\
$T_{M}\left[{ }^{\circ} \mathrm{C}\right]$ & 0.45 & 0.50 & 0.34 \\
$L_{\text {skin }[\mathrm{mm}]}$ & 0.23 & 0.70 & 0.38 \\
$\alpha_{m}[\mathrm{~mm} /$ day $]$ & 0.14 & 0.32 & 0.09 \\
$\phi[-]$ & 0.30 & 0.44 & 0.10 \\
$L P / F C[-]$ & 0.63 & 0.03 & -0.04 \\
$F C[\mathrm{~mm}]$ & 0.49 & 0.45 & 0.13 \\
$\beta[-]$ & 0.56 & 0.32 & 0.10 \\
$K_{0}[$ days $]$ & 0.25 & 0.31 & -0.04 \\
$K_{1}[$ days $]$ & 0.63 & 0.59 & -0.10 \\
$K_{2}[$ days $]$ & 0.42 & 0.38 & -0.09 \\
$C_{P}[\mathrm{~mm} /$ day $]$ & 0.57 & 0.57 & 0.14 \\
$L S_{U Z}[\mathrm{~mm}]$ & 0.44 & 0.37 & -0.13 \\
\hline
\end{tabular}

$\left.w_{r}=0.0\right)$ in two independent calibration periods (1991-1995 and 1996-2000). From their comparison it is clear that the most noticeable differences between the calibration variants are observed for the transfer factor $\alpha_{m}$. The model calibration with the use of scatterometer data $\left(w_{r}=0.65\right.$ and $w_{r}=0.0$ variants) resulted in generally smaller transfer parameter values than obtained by traditional runoff only calibration. On the other hand, the maximum storage capacity $L_{\text {skin }}$ and the fraction of actual evaporation $\phi$ parameters are better identifiable. The medians of $L_{\text {skin }}$ and $\phi$ parameters are approximately between 3 and $5 \mathrm{~mm}$ and between 0.88 and 0.90 in different calibration periods and variants, respectively.

\section{Discussion and conclusions}

This study compares top soil moisture estimates from the scatterometer and a conceptual hydrologic model. The hydrologic model simulates the soil moisture from observed daily air temperature and precipitation using model parameters, which need to be estimated by the calibration. The relative top soil moisture is obtained by relating the amount of water stored in the top soil layer (reservoir) to a model parameter $L_{\text {skin }}$ which defines the maximum capacity of that reservoir. On the other hand, the scatterometer estimates are based on the normalization of a backscatter signal which is rescaled between the driest and wettest observations in a long-term period. This indicates that two different top soil moisture estimates used in this study are not identically
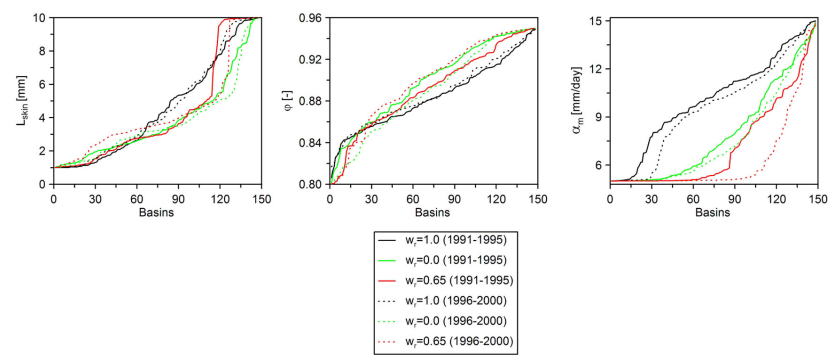

Fig. 11. Cumulative distribution functions (CDFs) of the top soil layer model parameters $\left(L_{\text {skin }}, \phi\right.$ and $\left.\alpha_{m}\right)$ obtained by three calibration variants: (1) runoff only calibration $\left(w_{r}=1.0\right),(2)$ soil moisture only calibration $\left(w_{r}=0.0\right)$ and (3) the multiple objective calibration $\left(w_{r}=0.65\right)$. CDFs represent 148 catchments in two calibration periods.

defined. The quantitative assessment of their differences showed that the hydrologic model generally simulates larger relative top soil moisture than what the scatterometer data indicate. This is an opposite finding to the studies of Ceballos et al. (2005) and Wagner et al. (1999), who compared the scatterometer to field soil moisture measurements. The differences found in this study, probably, are partly related to the different soil moisture definition, and partly related to the parameterization of the dual layer soil moisture scheme at a daily time step. Surface soil moisture tends to vary considerably in time. It has been shown that after only about $12 \mathrm{~h}$ difference in scatterometer observation time, the RMSE (root mean square error) of soil moisture estimation increases rapidly by more than $50 \%$ of its initial value (Naeimi et al., 2008 b). In a near future, we plan to simulate the soil moisture on an hourly time step, which seems to be more representative for a direct comparison of soil moisture values, especially for a more continuous emptying of the top soil moisture reservoir in the dual layer scheme.

The evaluation of the correlation between scatterometer and hydrologic model top soil moisture estimates indicated that in the flat regions of Austria, there is a close agreement in the tendency between the two datasets. On the other hand, in the alpine regions with complex terrain it is difficult to derive regionally consistent soil moisture estimates. Part of the poor correlations in the Alps may be due to the rugged terrain and forest cover which may make the scatterometer data less accurate than in the flatlands. The low correlations may also be due to unavailability of enough daily SCAT data especially in the calibration period of 1991-1996 and also only using the summer scatterometer data. This will reduce the seasonal sample variance which, with a given error variance, will decrease the correlation coefficient. This problem will be diminished in the future studies by using ASCAT data in calibration procedure, which provide uninterrupted data acquisition with more than twice data coverage than SCAT. Clearly, the soil moisture estimates from the hydrological simulations are also associated with considerable uncertainty. One 
would, however, not expect major differences in the uncertainty between the Alpine and lowland parts of Austria.

In this study we applied a parsimonious dual layer conceptual hydrologic model for top soil moisture simulations. When compared its efficiency to a classic single layer soil representation tested in Parajka et al. (2006) we found that the top model layer simulations fits more consistently to scatterometer values than does the single layer model to root zone scatterometer estimates. The median correlation coefficient over 148 catchments increased from 0.35 for the single layer to more than 0.46 for the dual layer model representations in the calibration period and from 0.25 (single layer) to 0.33 (dual layer) in the verification period. The results show that using SCAT soil moisture data in calibration process does not degrade the runoff model performance. The dual layer hydrologic model still performed slightly better, the median of runoff efficiency slightly increased from 0.78 (single layer) to 0.79 (dual layer) in the calibration period and from 0.76 (single layer) to 0.77 (dual layer) in the verification period.

The characterisation and matching of the multiscale variability of soil moisture is a challenging task, which, for example, can be investigated within the context of spatiotemporal filters, as addressed by Western et al. $(2002,2003)$ and Skøien and Blöschl (2006). Although it is not possible to define the soil moisture ground truth at the catchment scale, the comparison of two soil moisture datasets seems to be beneficial from both the remote sensing and hydrologic modeling perspectives. Our findings show that for remote sensing it is important to develop a more robust masking procedure in the scatterometer retrieval algorithm. The existence of snow or frozen ground (indicated e.g. by negative air temperatures) tends to decrease the scatterometer top soil moisture, which may bias the assimilation of scatterometer soil moisture into a hydrologic model. These findings are consistent with the conclusions of Pellarin et al. (2006) who suggested to apply a more robust freezing soil detection procedure in the retrieval algorithm.

From the hydrologic model perspective it is clear that the added value of scatterometer is especially in more robust estimation of individual water balance components. The use of additional scatterometer data in model calibration tends to reduce the parameter uncertainty of the top soil moisture and snow dynamics modules of the hydrologic model. We found that the improved top soil moisture agreement in the multiple objective calibration setting does not have any significant effects on the runoff model efficiency and thus provides an option for more robust water balance simulations in change assessment studies. In our next effort we plan to investigate this potential in more detail and to assimilate the spatial patterns of scatterometer soil moisture into a distributed hydrologic model.
Acknowledgements. The authors would like to thank the Austrian Science Foundation (FWF project no. P18993-N10), the Austrian Academy of Sciences, project HÖ 31 for financial support and the Austrian Hydrographic Service (HZB) for providing the hydrologic data.

Edited by: R. Ludwig

\section{References}

Bartalis, Z., Scipal, K., and Wagner, W.: Azimuthal anisotropy of scatterometer measurements over land, IEEE T. Geosci. Remote Sens., 44, 2083-2092, 2006.

Boni, G., Entekhabi, D., and Castelli, F.: Land data assimilation with satellite measurements for the estimation of surface energy balance components and surface control on evaporation, Water Resour. Res., 37(6), 1713-1722, 2001.

Ceballos, A., Scipal, K., Wagner W., and Martínez-Fernandez, J.: Validation of ERS scatterometer-derived soil moisture data in the central part of the Duero Basin, Spain, Hydrol. Process., 19, 1549-1566, 2005.

Crow, W. T., Bindlish, R., and Jackson, T. J.: The added value of spaceborne passive microwave soil moisture retrievals for forecasting rainfall-runoff partitioning, Geophys. Res. Lett., 32, L18401, doi:10.1029/2005GL023543, 2005.

de Wit, A. J. W. and van Diepen, C. A.: Crop model data assimilation with the ensemble Kalman filter for improving regional crop yield forecasts, Agr. Forest Meteorol., 146, 38-56, 2007.

Dirmeyer, P. A., Guo, Z., and Gao, X.: Comparison, validation, and transferability of eight multiyear global soil wetness products, $\mathrm{J}$. Hydrometeorol., 5, 1011-1033, 2004.

Duan, Q., Sorooshian, S., and Gupta, V. K.: Effective and efficient global optimization for conceptual rainfall-runoff models, Water Res. R., 28, 1015-1031, 1992.

Fontaine, B., Louvet, S., and Roucou, P.: Fluctuations in annual cycles and interseasonal memory in west africa: rainfall, soil moisture and heat fluxes, Theor. Appl. Climatol., 88, 57-70, 2006.

Francois, C., Quesney, A., and Ottlé, C.: Sequential Assimilation of ERS-1 SAR Data into a Coupled Land Surface - Hydrological Model Using an Extended Kalman Filter, J. Hydrometeorol., 4, 473-487, 2003.

Hoeben, R. and Troch, P. A.: Assimilation of active microwave observation data for soil moisture profile estimation, Water Res. R., 36(10), 2805-2819, 2000.

Houser, P., Goodrich, D., and Syed, K.: Runoff, precipitation, and soil moisture at Walnut Gulch, Chapter 6, in: Spatial Patterns in Catchment Hydrology: Observations and Modelling, edited by: Grayson, R. and Blöschl, G.: Cambridge University Press, Cambridge, 125-157, 2000.

Klemeš, V.: Operational testing of hydrological simulation models, Hydrol. Sci. J., 31, 13-24, 1986.

Merz, R. and Blöschl, G.: Regionalisation of catchment model parameters, J. Hydrol., 287, 95-123, 2004.

Mészároš, I. and Miklánek, P.: Calculation of potential evapotranspiration based on solar radiation income modeling in mountainous areas. Biologia, 61/Suppl. 19, 284-288, 2006.

Naeimi, V., Scipal, K., Bartalis, Z., Hasenauer, S., and Wagner, W.: An improved soil moisture retrieval algorithm for ERS and 
METOP scatterometer observations, IEEE T. Geosci. Remote Sens., in press, 2008a.

Naeimi, V., Bartalis, Z., and Wagner, W.: ASCAT soil moisture: An assessment of the data quality and consistency with the ERS scatterometer heritage, J. Hydrometeorol., doi:10.1175/2008JHM1051.1, in press, 2008b.

Parada, L. M. and Liang, X.: Optimal multiscale Kalman filter for assimilation of near-surface soil moisture into land surface models. J. Geophys. Res., 109, D24109, doi:10.1029/2004JD004745, 2004.

Parada, L. M. and Liang, X.: Impacts of spatial resolutions and data quality on soil moisture data assimilation, J. Geophys. Res., 113, D10101, doi:10.1029/2007JD009037, 2008.

Parajka, J., Merz, R., and Blöschl, G.: Estimation of daily potential evapotranspiration for regional water balance modeling in Austria, 11th, International Poster Day and Institute of Hydrology Open Day "Transport of Water, Chemicals and Energy in the Soil - Crop Canopy - Atmosphere System", Slovak Academy of Sciences, Bratislava, 299-306, 2003.

Parajka, J. and Blöschl, G.: The value of MODIS snow cover data in validating and calibrating conceptual hydrologic models, J. Hydrol., 240-258, doi:10.1016/j.jhydrol.2008.06.006, 2008.

Parajka, J., Merz, R., and Blöschl, G.: Uncertainty and multiple objective calibration in regional water balance modelling - Case study in 320 Austrian catchments, Hydrol. Proc., 21, 435-446, 2007.

Parajka, J., Naeimi, V., Blöschl, G., Wagner, W., Merz, R., and Scipal, K.: Assimilating scatterometer soil moisture data into conceptual hydrological models at the regional scale, Hydrol. Earth Syst. Sci., 10, 353-368, 2006, http://www.hydrol-earth-syst-sci.net/10/353/2006/.

Pauwels, R. N., Hoeben, R., Verhoest, N. E. C., De Troch, F. P., and Troch, P. A.: Improvements of TOPLATS-based discharge predictions through assimilation of ERS-based remotely-sensed soil moisture values, Hydrol. Proc., 16, 995-1013, 2002.

Pebesma, E. J.: Gstat user's manual, Dept. of Physical Geography, Utrecht University, Utrecht, The Netherlands, 100 pp., 2001.

Pellarin, T., Calvet, J. C., and Wagner W.: Evaluation of ERS scatterometer soil moisture products over a half-degree region in southwestern France; Geophysical Research Letters, 33, L17401, $1-6,2006$.
Reichle, R. H. and Koster, R. D.: Global assimilation of satellite surface soil moisture retrievals into the NASA Catchment land surface model, Geophys. Res. Lett., 32, L02404, doi:10.1029/2004GL021700, 2005.

Schuurmans, J. M., Troch, P. A., Veldhuizen, A. A., Bastiaanssen, W. G. M., and Bierkens, M. F. P.: Assimilation of remotely sensed latent heat flux in a distributed hydrological model, Adv. Water Res., 26, 151-159, 2003.

Scipal, K., Scheffler, C., Wagner, W.: Soil moisture-runoff relation at the catchment scale as observed with coarse resolution microwave remote sensing, Hydrol. Earth Syst. Sci., 9(3), 173-83, 2005.

Skøien, J. and Blöschl, G.: Catchments as space-time filters - a joint spatio-temporal geostatistical analysis of runoff and precipitation. Hydrol. Earth Syst. Sci., 10, 645-662, 2006, http://www.hydrol-earth-syst-sci.net/10/645/2006/.

Wagner, W., Lemoine, G., and Rott, H.: A method for estimating soil moisture from ERS scatterometer and soil data, Remote Sens. Environ., 70, 191-207, 1999.

Walker, J. P., Willgoose, G. R., and Kalma, J. D.: One-dimensional soil moisture profile retrieval by assimilation of near-surface observations: A comparison of retrieval algorithms, Adv. Water Resour., 24(6), 631-650, 2001.

Western, A., Grayson, R., and Blöschl, G.: Scaling of soil moisture: a hydrologic perspective, Ann. Rev. Earth Planet. Sci., 30, 149$180,2002$.

Western, A. W., Grayson, R., Blöschl, G., and Wilson, D. J.: Spatial variability of soil moisture and its implications for scaling, in: Scaling methods in soil physics, edited by: Pachepsky, Y., Radcliffe, D. E., and Selim, H. M., CRC Press, Boca Raton, 119-142, 2003.

Wigneron, J. P., Olioso, A., Calvet, J. C., and Bertuzzi, P.: Estimating root zone soil moisture from surface soil moisture data and soil-vegetation-atmosphere transfer modelling, Water Res. R., 35(12), 3735-3745, 1999.

Zhao, D., Su, B., and Zhao, M.: Soil moisture retrieval from satellite images and its application to heavy rainfall simulation in eastern China, Adv. Atmos. Sci., 23, 299-316, 2006. 